\title{
Blockade of ankyrin repeat-rich membrane spanning protein modulates extracellular signal-regulated kinase expression and inhibits allergic inflammation in ovalbumin-sensitized mice
}

\author{
XIUQIN NI ${ }^{1,2}$, XING LI $^{3}$, SHUHUA TAO $^{2}$, MINGHUI XU' ${ }^{2}$, HONGMEI MA $^{2}$ and XIULI WANG ${ }^{2}$ \\ ${ }^{1}$ Department of Anatomy, Harbin Medical University-Daqing, Daqing, Heilongjiang 163319; \\ ${ }^{2}$ Biopharmaceutical Institute, Heilongjiang Academy of Medical Sciences, Harbin, Heilongjiang 150081; \\ ${ }^{3}$ Department of Nephrology, Daqing People's Hospital, Daqing, Heilongjiang 163310, P.R. China
}

Received March 16, 2013; Accepted May 24, 2013

DOI: $10.3892 /$ br.2013.120

\begin{abstract}
Ankyrin repeat-rich membrane spanning protein (ARMS), also known as kinase D-interacting substrate of $220 \mathrm{kDa}$ (Kidins220), is a transmembrane protein that has been reported to be involved in the pathogenesis of asthma through the nerve growth factor (NGF)/tyrosine kinase A (TrkA) receptor signaling pathway. To investigate whether NGF/TrkA-Kidins220/ARMS-extracellular signal-regulated kinase (ERK) signaling is activated in airway inflammation of asthma, BALB/c mice were sensitized and challenged with ovalbumin (OVA). The effects of Kidins220/ARMS on ERK, interleukin (IL)-1 $\beta$, IL-4 and tumor necrosis factor (TNF)- $\alpha$ in lung tissues following the allergic airway challenge in mice were assessed by administering anti-ARMS antibody to the mice. Pathological changes in the bronchi and lung tissues were examined via hematoxylin and eosin staining. The phosphorylated ERK, IL-1 $\beta$, IL-4 and TNF- $\alpha$ levels were determined using western blot analysis and ELISA and were found to be overexpressed in lung tissues following the allergen challenge. Moreover, after the mice were treated with anti-NGF, anti-TrkA or anti-ARMS, the levels of Kidins220/ARMS, phosphorylated ERK, IL-1 $\beta$, IL-4, TNF- $\alpha$ and allergen-induced airway inflammation were downregulated. These results suggested that NGF/TrkA-Kidins220/ARMS-ERK signaling was activated in airway inflammation induced by the allergic airway challenge, possibly representing a new mechanism in asthma.
\end{abstract}

Correspondence to: Dr Xiuqin Ni, Department of Anatomy, Harbin Medical University-Daqing, Daqing, Heilongjiang 163319, P.R. China E-mail: nxq200285@163.com

Key words: ankyrin repeat-rich membrane spanning protein, kinase D-interacting substrate of $220 \mathrm{kDa}$, extracellular signal-regulated kinase, asthma

\section{Introduction}

Ankyrin repeat-rich membrane spanning protein (ARMS), also known as kinase D-interacting substrate of $220 \mathrm{kDa}$ (Kidins220), is an important molecule in the nerve growth factor (NGF)/tyrosine kinase A (TrkA) receptor signaling pathway, as it binds to NGF-TrkA, activating downstream enzymes (1). An association between TrkA and ARMS was previously found to persist for several hours (2). During NGF-induced neuronal differentiation, there is direct engagement of the TrkA receptor with ARMS, leading to sustained mitogen-activated protein kinase (MAPK) activation that regulates neurite outgrowth (3). Numerous inflammatory cytokines and polypeptide growth factors elicit specific cell responses through the activation of MAPK cascades $(4,5)$. Among the best characterized of the mammalian MAPK superfamily of serine/threonine kinases are the p42- and p44-kDa extracellular signal-regulated kinases (ERKs) ERK2 and ERK1 (collectively defined as p42/p44 ERK), the p38 MAPK and the p46-p54-kDa c-Jun amino (N)-terminal kinase (JNK) or stress-activated protein kinase (6). A previous study demonstrated that ERK activity in the lungs of asthmatic mice was significantly higher compared to that in normal mice (7). We recently demonstrated that the expression of ARMS in lung tissues was increased in asthmatic mice compared to that in control mice $(8,9)$.

Asthma is characterized by chronic airway inflammation. Numerous cell types and cytokines contribute to this inflammation (10). The NGF-mediated TrkA pathway was reported to be involved in the pathogenesis of asthma. In addition, interleukin (IL)-1 $\beta$ and tumor necrosis factor (TNF)- $\alpha$ were shown to exert a prominent effect on the development of airway responsiveness and airway inflammation in bronchial asthma (11,12). IL-4 is a Th2 cytokine that plays important roles in allergic inflammation and airway remodeling $(13,14)$. The total and phosphorylated (activated) forms of ERK are present in dorsal root ganglion (DRG), satellite and Schwann cells. The basal levels of activated ERK in DRG cells are low, although they are selectively increased in calcitonin gene-related peptide/TrkA cells with NGF treatment (15). IL-1 $\beta$ activates $\mathrm{p} 42 / \mathrm{p} 44$ ERK-dependent processes in human 
airway smooth muscle (ASM). p42/p44 ERK affects the extent of IL-1 $\beta$-stimulated cytokine release $(6,16)$. The synergistic action of the ERK and p38 MAPK pathways is required for the optimal induction of cytokine gene expression (17) and cytokine release (18). NGF may be involved in the pathogenesis of neurogenic inflammation in asthma through the Ras-MAPK signal transduction pathway. NGF/TrkA and ARMS were reported to participate in the pathogesis of asthma $(8,9)$. Kidins220/ARMS is a novel component of the uropod involved in the regulation of T-cell motility, an essential process for the immune response (19). The ERK signaling pathway may modulate allergic airway inflammation $(7,20)$. However, whether the ARMS-mediated ERK signaling pathway is also involved in the inflammation of asthma has not been elucidated.

Based on the above findings, we hypothesized that Kidins220/ARMS-mediated ERK signaling pathway may be involved in the inflammation of asthma. Our findings demonstrated that ERK and ARMS were overexpressed in lung tissues following the allergen challenge and the increased expression of p42/p44 ERK was decreased with anti-NGF, anti-TrkA or anti-ARMS antibody treatment.

\section{Materials and methods}

Animals. A total of 62 female BALB/c mice, 6- to 8-weeks-old, weighing 18-22 g, were obtained from the Beijing Laboratory Animal Research Center (Beijing, China). The mice were maintained under specific pathogen-free conditions. An ovalbumin (OVA)-free diet and water were supplied ad libitum. The animal studies were approved by the Ethics Committee for Animal Use and Care at the Institute of Education of China Medical University.

Sensitization, challenge and treatment. The BALB/c mice were randomized into five groups: control $(n=12)$, OVA $(n=14)$, anti-NGF $(n=12)$, anti-TrkA $(n=12)$ and anti-ARMS $(n=12)$. Sensitization and challenge protocols were conducted according to the methods of Elwood et al (21) and Vanacker et al (22), with certain modifications, as described below. In the OVA group, mice were sensitized to ovalbumin $(20 \mu \mathrm{g}$ per injection) absorbed in $2.0 \mathrm{mg}$ per injection of aluminium hydroxide administered intraperitoneally on day 1 . On days 8,15 and 22 , mice were again sensitized to ovalbumin (10 $\mu \mathrm{g}$ per injection) absorbed in $1.0 \mathrm{mg}$ per injection of aluminium hydroxide administered intraperitoneally. Beginning on day 23, the mice were administered inhaled aerosols of $4 \%$ ovalbumin in phosphate-buffered saline (PBS) for 25-30 min (until the onset of bronchial obstruction) daily for 7 consecutive days. The mice in the anti-NGF, anti-TrkA and anti-ARMS groups were also subjected to ovalbumin sensitization and asthma induction in the same manner. Intranasal administration of $50 \mu 1$ (1:50 dilution) of polyclonal goat anti-mouse NGF antibody (biological activity: 1:4,000 dilution blocks bioactivity of $5 \mathrm{ng} / \mathrm{ml} \mathrm{NGF}$ ) (Santa Cruz Biotechnology, Inc., Santa Cruz, CA, USA) dissolved in sterile PBS was performed $3 \mathrm{~h}$ prior to each airway allergen challenge in the anti-NGF group. Intranasal treatment with anti-NGF antibody was performed according to the methods of Braun et al (23), Glaab et al (24) and Nagai et al (25), with minor modifications. The mice in the anti-TrkA group received $0.2-\mathrm{mmol} / 1$ anti-TrkA antibody
(200 ml prepared with PBS) (Santa Cruz Biotechnology, Inc.) by intranasal administration $(26,27) 3 \mathrm{~h}$ prior to the induction of asthma. Mice in the anti-ARMS group received intranasal goat polyclonal anti-ARMS antibody (diluted 1:25 in PBS) (Santa Cruz Biotechnology, Inc.). Mice in the control group were challenged with PBS alone, administered by injection. All the animals were humanely sacrificed within $24 \mathrm{~h}$ after the last ovalbumin or PBS exposure.

Pathological examination of bronchial and lung tissues. The lungs of the BALB/c mice were perfused with $4 \%$ paraformaldehyde to allow the pleura to extend and flatten prior to fixation of the tissue in $4 \%$ paraformaldehyde. The tissues were routinely embedded in paraffin and sectioned $(5 \mu \mathrm{m})$ for hematoxylin and eosin staining to assess the pathological changes in the lung and bronchial tissues under a microscope.

Western blot analysis for ERK. Protein homogenates of lung tissue samples were prepared by rapid homogenization in 10 volumes of ice-cold RIPA lysis buffer (Beyotime, Shanghai, China). The protein concentrations of the tissue lysates were determined using the Enhanced BCA Protein Assay kit (Beyotime) and the supernatants were boiled in sodium dodecyl sulfate sample buffer for $5 \mathrm{~min}$. Equal amounts of lysate proteins were separated using $10 \%$ sodium dodecyl sulfate-polyacrylamide gel electrophoresis and transferred onto a polyvinylidene difluoride membrane (Amersham Pharmacia Biotech, Uppsala, Sweden). After blocking, the blots were incubated with specific primary antibody overnight at $4^{\circ} \mathrm{C}$ and were then further incubated for $1 \mathrm{~h}$ with horseradish peroxidase-conjugated secondary antibody. The bound antibodies were detected using an enhanced chemiluminescence kit with a Lumino-Image analyzer (Taitec Corp, Tokyo, Japan). Integrated density values were analyzed using a computerized image analysis system (Fluor Chen 2.0) and normalized to those of $\beta$-actin.

ELISA for IL-1 $\beta, I L-4$ and TNF- $\alpha$ levels in lung tissues. Lung tissues $(50 \mathrm{mg} / 500 \mu \mathrm{l})$ were homogenized in PBS using a Polytron homogenizer (Kinematica, Littau, Switzerland), then centrifuged at $800 \mathrm{xg}$ for $10 \mathrm{~min}$. The protein levels of IL-1 $\beta$, IL-4 and TNF- $\alpha$ in the lung tissue homogenates (50 $\mu \mathrm{l})$ were determined by ELISA, according to the manufacturer's instructions (Bionewtrans Pharmaceutical Biotechnology Co., Ltd., Franklin, MA, USA). The limit of detection for IL-1 $\beta$, IL-4 and TNF- $\alpha$ was $>1,1$ and $7.8 \mathrm{pg} / \mathrm{ml}$, respectively.

Statistical analysis. The data were analyzed using SPSS statistical software version 15.0 (SPSS Inc, Chicago, IL, USA) and were expressed as mean \pm standard deviation. Differences between groups were analyzed, as appropriate, using the Student's t-test and one-way analysis of variance followed by the Fisher's least significant difference test. $\mathrm{P}<0.05$ was considered to indicate a statistically significant difference.

\section{Results}

Pathological changes in the bronchial and lung tissues. The mice in the control group exhibited normal smooth bronchial and alveolar structures. There was no inflammatory cell 

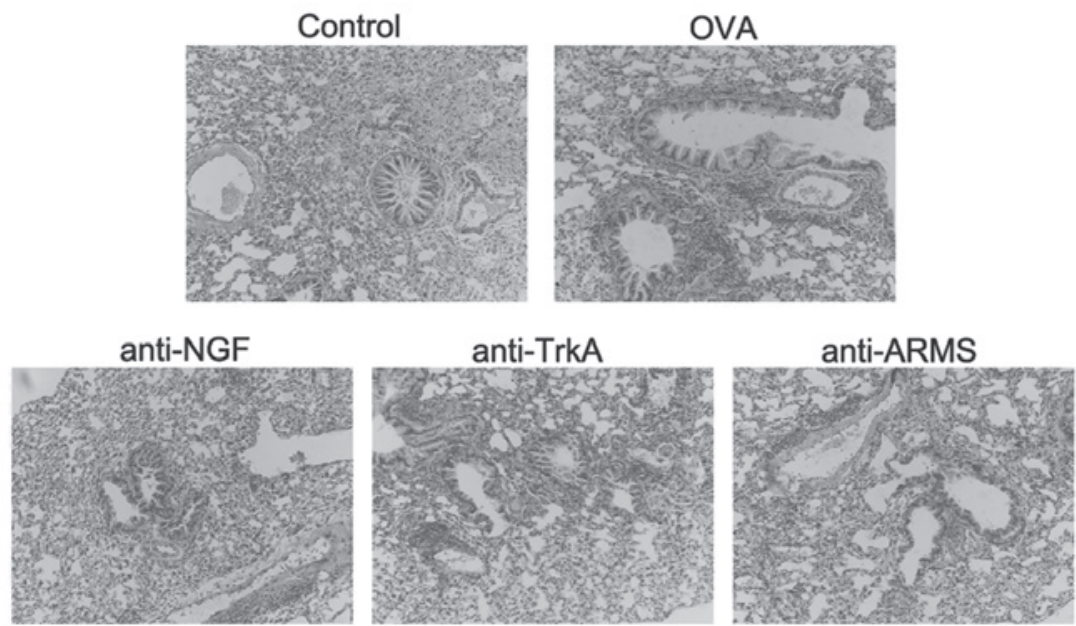

Figure 1. Pathological changes in the bronchial and lung tissues of BALB/c mice in the different groups. A distinct bronchiolar stenosis is observed in the ovalbumin (OVA) group, with inflammatory cell infiltration of bronchiolar and lung tissue. The inflammation and bronchiolar narrowing were significantly alleviated after intervention with the anti-NGF, anti-TrkA and anti-ARMS antibodies. Sections were stained with hematoxylin and eosin (original magnification, x200). ARMS, anti-ankyrin repeat-rich membrane spanning; NGF, nerve growth factor; TrkA, tyrosine kinase A.
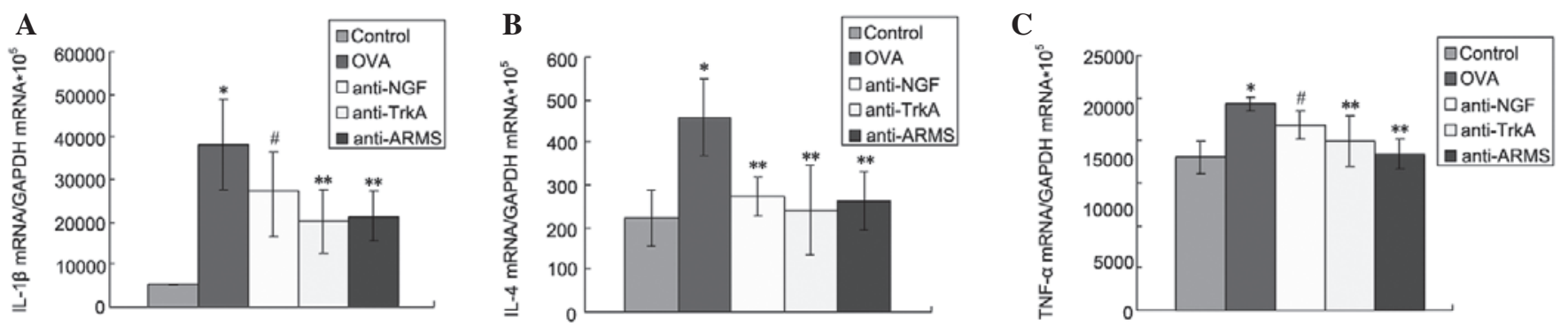

Figure 2. Effect of anti-ARMS treatment on interleukin (IL)-1 $\beta$, IL-4 and tumor necrosis factor (TNF)- $\alpha$ levels. (A) IL-1 $\beta$, (B) IL-4 and (C) TNF- $\alpha$ levels in lung tissues were measured by ELISA. Data are expressed as mean \pm standard deviation $(\mathrm{n}=6)$. ${ }^{*} \mathrm{P}<0.01$ vs. control group; ${ }^{* * *} \mathrm{P}<0.01$ and ${ }^{\#} \mathrm{P}<0.05$ vs. ovalbumin (OVA) group. ARMS, anti-ankyrin repeat-rich membrane spanning; TrkA, tyrosine kinase A; NGF, nerve growth factor; GAPDH, Glyceraldehyde 3-phosphate dehydrogenase

infiltration of the airway and lung tissues. The mice in the OVA group exhibited an extensive inflammatory cell infiltration around the bronchioles, blood vessels and alveoli. The airway mucosa was edematous, with bronchiolar wall thickening causing luminal stenosis, suggesting successful establishment of the asthmatic model. In asthmatic mice treated with anti-NGF, anti-TrkA and anti-ARMS antibodies, the extent of inflammation and cellular infiltration in the airway was reduced and the pathological changes of the bronchial and lung tissues were milder compared to those in the asthma group (Fig. 1).

$I L-1 \beta, I L-4$ and $T N F-\alpha$ concentration in lung tissues. The concentration of IL-1 $\beta$, IL-4 and TNF- $\alpha$ in the lung tissues was significantly higher in the OVA compared to the control group $(\mathrm{P}<0.01)$. The expression of IL-1 $\beta$, IL- 4 and TNF- $\alpha$ was reduced following treatment with anti-NGF, anti-TrkA and anti-ARMS antibodies, providing direct evidence that ARMS may affect the expression of inflammatory cytokines in lung tissues and suggesting the possible involvement of NGF/TrkA-ARMS signaling in inflammatory reactions in asthma (Fig. 2).

Expression of $p E R K$. Western blot analysis was performed to measure the levels of pERK/ERK in the lung tissues in each group (Fig. 3). The control group exhibited low expression
A

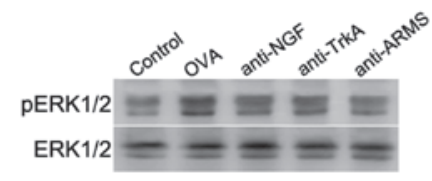

B

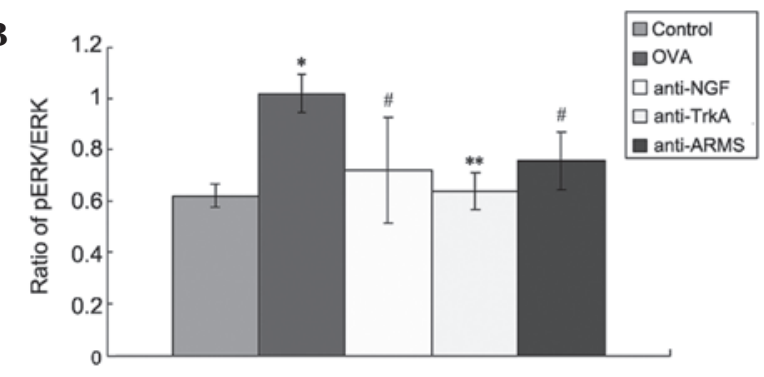

Figure 3. Expression of p-extracellular signal-regulated kinase (pERK) in lung tissues by western blot analysis. (A) Expression of pERK and ERK in the control, ovalbumin (OVA), anti-NGF, anti-TrkA and anti-ankyrin repeat-rich membrane spanning (ARMS) group; (B) optical density values for $\mathrm{pERK}$ relative to ERK. Data are expressed as mean \pm standard deviation $(\mathrm{n}=6)$. ${ }^{*} \mathrm{P}<0.01$ vs. control group; ${ }^{* *} \mathrm{P}<0.01$ and ${ }^{\#} \mathrm{P}<0.05$ vs. OVA group. NGF, nerve growth factor; TrkA, tyrosine kinase A.

levels of pERK/ERK. However, the levels were significantly increased in the OVA group $(\mathrm{P}<0.01)$. Furthermore, the expression of pERK in the anti-NGF, anti-TrkA and anti-ARMS 
groups was significantly lower compared to that in the OVA group $(\mathrm{P}<0.01)$.

\section{Discussion}

In this study, we demonstrated that the expression of pERK in lung tissues, as determined by western blot analysis, was increased in the OVA group compared to that in the control group. Intervention with anti-ARMS, anti-NGF and anti-TrkA antibodies resulted in a significant reduction of pERK expression in lung tissues in the OVA group. ARMS blockade was also associated with reduced cytokine levels in the lung tissues of OVA-sensitized mice. It was previously demonstrated that NGF/TrkA plays an important role in bronchial hyperresponsiveness and inflammation $(28,29)$ in asthma. Kidins220/ARMS, a novel transmembrane protein substrate of Trk receptors, is directly involved in the downstream signaling events for neurotrophins. ARMS was identified as an important molecule in the signaling pathway, as it binds to NGF-TrkA and activates downstream enzymes (1). ARMS also serves as a substrate for protein kinase D (30). The interaction between Trk and ARMS was shown to result in an increase in MAPK activation that persists for several hours.

The MAPK signaling cascade has been shown to be important in the activation of various immune cells (31). Three major groups of MAPK are encountered in mammalian cells, including extracellular signal-regulated protein kinase (ERK), p38 MAPK and JNK. The regulation of the ERK signaling pathway may modulate allergic airway inflammation (20). Kidins220/ARMS knockout mice exhibited developmental defects, mainly in the nervous and cardiovascular systems, suggesting a crucial role for this protein in the modulation of the crosstalk between different signaling pathways (32). Therefore, it may be assumed that the NGF-TrkA-ARMS signaling pathway is involved in the inflammation associated with asthma by activating ERK.

TrkA, as a receptor tyrosine kinase, traditionally signals through the activation of one of three major biochemical pathways: phospholipase C $\gamma$ (PLC $\gamma)$, p42/p44 ERK (ERK1/2) or phosphatidylinositol-3-kinase (PI3K). MAPK activation is known to play a crucial role in the proliferation of ASM cells induced by various mitogens. Activation of ASM cells by IL-1 $\beta$ also leads to the production of mediators and numerous cytokines and chemokines (33). These effects are regulated to some extent by MAPK activation (34). Allergic airway inflammation involves multiple inflammatory cells and a wide array of mediators (35). It was previously demonstrated that the activation of ARMS is mainly realized by the MAPK signaling pathway (20). Specific cytokines were associated with human asthma through examinations of blood, exhaled breath condensates, bronchoalveolar lavage fluid (BALF) cells or sputum cells (36). Increased amounts of IL-1 $\beta$ and TNF- $\alpha$ were detected in BALF (37) and in the culture supernatants of alveolar macrophages from asthmatic patients (11). Moreover, the level of the pro-inflammatory cytokine IL-4 is increased in the lung tissues of asthmatic human (38) and animal subjects $(39,40)$. The cytokines IL- $1 \beta$, IL- 4 and TNF- $\alpha$ are key elements in the airway inflammation and hyperresponsiveness observed in allergic asthma. Th1-associated IL-1 $\beta$ and TNF- $\alpha$, as well as Th2-associated IL-4, are considered as the key cytokines involved in the induction of airway hyperresponsiveness, infiltration of eosinophils into the lungs and mucus secretion (41). The ERK signaling pathway was shown to be involved in the cytokine production by a variety of cell types (42-44). However, whether the ARMS-mediated ERK signaling pathway is involved in asthma inflammation and its underlying mechanisms has not yet been elucidated.

This study demonstrated that ARMS inhibition effectively reduced OVA-induced cytokine production in a mouse asthma model. The expression of IL-1 $\beta$, IL-4 and TNF- $\alpha$ in the lungs of OVA-sensitized mice was higher compared to that in control mice. ERK activation was also observed in the lung tissues of OVA-sensitized mice. However, treatment with anti-NGF, anti-TrkA and anti-ARMS antibodies resulted in downregulation of the expression of IL-1 $\beta$, IL-4 and TNF- $\alpha$ in OVA-sensitized mice. Moveover, intervention with anti-ARMS antibody resulted in a significant reduction of NGF and TrkA and activation of ERK. These results suggested that the NGF/TrkA-ARMS-ERK signaling pathway activated by airway inflammation in allergic asthma may be involved in the pathogenetic mechanism of asthma through the upregulation of IL-1 $\beta$, IL- 4 and TNF- $\alpha$ expression. These results indicate that ARMS-mediated ERK pathway plays a role in the inflammatory response and that ARMS and pERK upregulation is involved in the neuroimmunological pathogenesis of the allergen challenge in mice. These findings may lead to the development of novel therapeutic approaches to allergic diseases of the airways.

In conclusion, the present study has demonstrated that NGF/TrkA-Kidins220/ARMS-ERK signaling contributes to airway inflammation in OVA-sensitized mice. Intranasal administration of anti-NGF, anti-TrkA and anti-ARMS antibodies effectively blocked the inflammatory cascade. Our results support the hypothesis that the NGF/TrkA-ARMS signaling pathway may be involved in the inflammation of asthma via ERK activation. Identification of NGF/TrkAKidins220/ARMS-ERK signaling may prove useful in the treatment of allergic airway inflammation.

\section{Acknowledgements}

This study was supported by the Education Department Project of Heilongjiang Province (contract no. 12511218).

\section{References}

1. Edwards MR, Bartlett NW, Clarke D, Birrell M, Belvisi M and Johnston SL: Targeting the $N F-\kappa B$ pathway in asthma and chronic obstructive pulmonary disease. Pharmacol Ther 121: 1-13, 2009.

2. Kong H, Boulter J, Weber JL, Lai C and Chao MV: An evolutionarily conserved transmembrane protein that is a novel downstream target of neurotrophin and ephrin receptors. J Neurosci 21: 176-185, 2001.

3. Arevalo JC, Yano H, Teng KK and Chao MV: A unique pathway for sustained neurotrophin signaling through an ankyrin-rich membrane-spanning protein. EMBO J 23: 2358-2368, 2004.

4. Davids RJ: The mitogen-activated protein kinase signal transduction pathway. J Biol Chem 268: 14553-14556, 1993.

5. Robinson MJ and Cobb MH: Mitogen-activated protein kinase pathways: Curr Opin Cell Biol 9: 180-186, 1997.

6. Hallsworth MP, Moir LM, Lai D and Hirst SJ: Inhibitors of mitogen-activated protein kinases differentially regulate eosinophil-activating cytokine release from human airway smooth muscle. Am J Respir Crit Care Med 164: 688-697, 2001. 
7. Kumar A, Lnu S, Malya R, Barron D, Moore J, Corry DB and Boriek AM: Mechanical stretch activates nuclear factor- $\kappa \mathrm{B}$, activator protein-1, and mitogen-activated protein kinases in lung parenchyma: implications in asthma. FASEB J 17: 1800-1811, 2003.

8. NiX,LiX, Fang X,LiN, CuiW and Zhang B: NGF/TrkA-mediated Kidins220/ARMS signaling activated in the allergic airway challenge in mice. Ann Allergy Asthma Immunol 105: 299-306, 2010.

9. Ni X, Li X, Fang X, Li N, Cui W, Zhang B and Liu Y: Kidins220/ARMS contributes to airway inflammation and hyper-responsiveness in OVA-sensitized mice. Respir Physiol Neurobiol 175: 97-103, 2011.

10. Ying S, Zhang G, Gu S and Zhao J: How much do we know about atopic asthma: where are we now? Cell Mol Immunol 3: 321-332, 2006.

11. Gosset P, Tsicopoulos A, Wallaert B, Vannimenus C, Joseph M, Tonnel $\mathrm{AB}$ and Capron $\mathrm{A}$ : Increased secretion of tumor necrosis factor alpha and interleukin- 6 by alveolar macrophages consecutive to the development of the late asthmatic reaction J Allergy Clin Immunol 88: 561-571, 1991.

12. Wills-Karp M, Uchida Y, Lee JY, Jinot J, Hirata A and Hirata F: Organ culture with proinflammatory cytokines reproduces impairment of the beta-adrenoceptor-mediated relaxation in tracheas of a guinea pig antigen model. Am J Respir Cell Mol Biol 8: 153-159, 1993.

13. Jie Z, Jin M, Cai Y, et al: The effects of Th2 cytokines on the expression of ADAM33 in allergen-induced chronic airway inflammation. Respir Physiol Neurobiol 168: 289-294, 2009.

14. Yoshinaka T, Nishii K, Yamada K, et al: Identification and characterization of novel mouse and human ADAM33s with potential metalloprotease activity. Gene 282: 227-236, 2002.

15. Averill S, Delcroix JD, Michael GJ, Tomlinson DR, Fernyhough P and Priestley JV: Nerve growth factor modulates the activation status and fast axonal transport of ERK1/2 in adult nociceptive neurons. Mol Cell Neurosci 18: 183-196, 2001.

16. Boehme SA, Sullivan SK, Crowe PD, Santos M, Conlon PJ, Sriramarao P and Bacon KB: Activation of mitogen-activated protein kinase regulates eotaxin-induced eosinophil migration. J Immunol 163: 1611-1618, 1999.

17. Hoffmeyer A, Grosse-Wilde A, Flory E, Neufeld B, Kunz M, Rapp UR and Ludwig S: Different mitogen-activated protein kinase signaling pathways cooperate to regulate tumor necrosis factor alpha gene expression in T lymphocytes. J Biol Chem 274 4319-4327, 1999

18. Maruoka S, Hashimoto S, Gon Y, Takeshita I and Horie T: PAF-induced RANTES production by human airway smooth muscle cells requires both p38 MAP kinase and Erk. Am J Respir Crit Care Med 161: 922-929, 2000.

19. Jean-Mairet RM, López-Menéndez C, Sánchez-Ruiloba L, et al: The neuronal protein Kidins220/ARMS associates with ICAM-3 and other uropod components and regulates T-cell motility. Eur J Immunol 41: 1035-1046, 2011.

20. Duan W, Chan JH, Wong CH, Leung BP and Wong WS: Anti-inflammatory effects of mitogen-activated protein kinase kinase inhibitor U0126 in an asthma mouse model. J Immunol 172: 7053-7059, 2004.

21. Elwood W, Lotvall JO, Barnes PJ and Chung KF: Characterization of allergen-induced bronchial hyperresponsiveness and airway inflammation in actively sensitized brown-Norway rats. J Allergy Clin Immunol 88: 951-960, 1991

22. Vanacker NJ, Palmans E, Kips JC and Pauwels RA: Fluticasone inhibits but does not reverse allergen-induced structural airway changes. Am J Respir Crit Care Med 163: 674-679, 2001.

23. Braun A, Appel E, Baruch R, et al: Role of nerve growth factor in a mouse model of allergic airway inflammation and asthma. Eur J Immunol 28: 3240-3251, 1998.

24. Glaab T, Hoymann HG, Hecht M, et al: Effect of anti-nerve growth factor on early and late airway responses in allergic rats. Allergy 58: 900-904, 2003.

25. Nagai T, Arai Y, Emori M, Nunome SY, Yabe T, Takeda T and Yamada H: Anti-allergic activity of a Kampo (Japanese herbal) medicine 'Sho-seiryu-to (Xiao-Qing-Long-Tang)' on airway inflammation in a mouse model. Int Immunopharmacol 4 : 1353-1365, 2004.
26. de Vries A, Engels F, Henricks PA, et al: Airway hyper-responsiveness in allergic asthma in guinea-pigs is mediated by nerve growth factor via the induction of substance P: a potential role for trkA. Clin Exp Allergy 36: 1192-1200, 2006.

27. Li L, Kong L, Fang X, et al: SH2-B $\beta$ expression in alveolar macrophages in BAL fluid of asthmatic guinea pigs and its role in NGF-TrkA-mediated asthma. Respirology 14: 60-68, 2009.

28. Frossard N, Naline E, Olgart Hoglund C, Georges O and Advenier C: Nerve growth factor is released by IL-1beta and induces hyperresponsiveness of the human isolated bronchus. Eur Respir J 26: 15-20, 2005

29. Nockher WA and Renz H: Neurotrophins in allergic diseases: from neuronal growth factors to intercellular signaling molecules. J Allergy Clin Immunol 117: 583-589, 2006.

30. Iglesias T, Cabrera-Poch N, Mitchell MP, Naven TJ, Rozengurt E and Schiavo G: Identification and cloning of Kidins220, a novel neuronal substrate of protein kinase D. J Biol Chem 275: 40048-40056, 2000

31. Chang L and Karin M: Mammalian MAP kinase signalling cascades. Nature 410: 37-40, 2001

32. Neubrand VE, Cesca F, Benfenati $F$ and Schiavo G: Kidins220/ARMS as a functional mediator of multiple receptor signalling pathways. J Cell Sci 125 (Pt 8): 1845-1854, 2012.

33. Chung KF: Airway smooth muscle cells: contributing to and regulating airway mucosal inflammation? Eur Respir J 15: 961-968, 2000

34. Moore PE, Church TL, Chism DD, Panettieri RA Jr and Shore SA: IL-13 and IL-4 cause eotaxin release in human airway smooth muscle cells: a role for ERK. Am J Physiol Lung Cell Mol Physiol 282: L847-L853, 2002.

35. Jorritsma PJ, Brogdon JL and Bottomly K: Role of TCR-induced extracellular signal-regulated kinase activation in the regulation of early IL-4 expression in naive CD4 ${ }^{+} \mathrm{T}$ cells. J Immunol 170: 2427-2434, 2003

36. Finkelman FD, Hogan SP, Hershey GK, Rothenberg ME and Wills-Karp M: Importance of cytokines in murine allergic airway disease and human asthma. J Immunol 184: 1663-1674, 2010.

37. Tillie-Leblond I, Pugin J, Marquette CH, et al: Balance between pro-inflammatory cytokines and their inhibitors in bronchial lavage from patients with status asthmaticus. Am J Respir Crit Care Med 159: 487-494, 1999.

38. Zimmermann N, Hershey GK, Foster PS and Rothenberg ME: Chemokines in asthma: cooperative interaction between chemokines and IL-13. J Allergy Clin Immunol 111: 227-242, 2003.

39. Secor ER, Carson WF, Singh A, Pensa M, Guernsey LA, Schramm CM and Thrall RS: Oral bromelain attenuates inflammation in an ovalbum-induced murine model of asthma. Evid Based Complement Alternat Med 5: 61-69, 2008.

40. Yin H, Jin XB, Gong Q, Yang H, Hu LY, Gong FL and Zhu JY: Fructose-1,6-diphosphate attenuates acute lung injury induced by lipopolysaccharide in mice. Int Immunopharmacol 8: 1842-1847, 2008.

41. Nakae S, Lunderius C, Ho LH, Schafer B, Tsai M and Galli SJ: TNF can contribute to multiple features of ovalbumin-induced allergic inflammation of the airways in mice. J Allergy Clin Immunol 119: 680-686, 2007.

42. Cui CH, Adachi T, Oyamada H, et al: The role of mitogen-activated protein kinases in eotaxin-induced cytokine production from bronchial epithelial cells. Am J Respir Cell Mol Biol 27: 329-335, 2002.

43. Lorentz A, Klopp I, Gebhardt T, Manns MP and Bischoff SC: Role of activator protein 1 , nuclear factor- $\mathrm{\kappa} \mathrm{B}$, and nuclear factor of activated $\mathrm{T}$ cells in IgE receptor-mediated cytokine expression in mature human mast cells. J Allergy Clin Immunol 111: 1062-1068, 2003.

44. Langdon C, Kerr C, Tong L and Richards CD: Oncostatin M regulates eotaxin expression in fibroblasts and eosinophilic inflammation in C57BL/6 mice. J Immunol 170: 548-555, 2003. 